\title{
JOSÉ DONOSO: \\ EL OTRO COLOQUIO DE LOS PERROS
}

\author{
POR \\ ALICIA BoRInsKy \\ Boston University
}

\begin{abstract}
El presente trabajo es una versión del último capítulo de un libro, Fábulas teóricas, donde elaboro las poéticas de la narrativa latinoamericana contemporánea. Mi estudio tiende a demostrar que es a través de la ficción que se cumplen los objetivos de lucidez acerca del lenguaje propuestos por el teórico-crítico. Enhebro, así, una serie de problemáticas acerca del lenguaje en escritores como Macedonio Fernández, Borges, María Luisa Bombal, Manuel Puig, Bioy Casares, García Márquez, Cortázar y José Donoso, entre otros, para demostrar el rigor de la poética que constituye la obra de cada uno y sus mutuas interconexiones. El libro sugiere una factura múltiple para lo teórico y estudia la literatura en relación con otras artes y la cultura popular.
\end{abstract}

\section{LA BIBLIOTECA VACÍA}

En El amor en los tiempos del cólera García Márquez nos ofrece una parodia de la francofilia criolla en la forma del loro que habla francés y que termina precipitando la muerte de su dueño en el transcurso de una sesión de intercambios aparentemente anodinos. Casa de campo de José Donoso hace una intervención igualmente lúdica pero mucho más intensa en la evaluación de lo francés en sus entrecuzamientos con una narrativa en castellano a través del juego "La marquesa salió a las cinco", cuya ubicuidad signa las relaciones entre los personajes de la novela. El frecuentemente citado ataque de Valéry contra el género novelístico reaparece en Donoso traducido al castellano. Como la novela abunda en frases, canciones, títulos en otros idiomas, la aparición de "La Marquesa salió a las cinco" en traducción en vez del original produce inmediatamente un efecto de desplazamiento paródico.

Casa de campo se centra en la suerte de un grupo de primos supuestamente abandonados por sus padres en la compañía de sirvientes mientras los mayores parten de viaje. Los primos habitan en una mansión rodeada de nativos empobrecidos. El escenario enfatiza contrastes, privilegios y sugiere posibles violencias. Los niños, en una atmósfera de presagios, intuyen la posibilidad de que sus padres nunca regresen de un viaje que, sin embargo, los trae de vuelta a un reencuentro donde el asco suplanta la formalidad de las despedidas iniciales. En el transcurso de la espera - la mayor parte de la novela- los niños juegan a "La Marquesa salió a las cinco" y practican entrecruzamientos sexuales 
transgresivos, ocasionalmente crueles y humillantes mientras los sirvientes se rebelan momentáneamente en un conato revolucionario que será aplacado. La brutalidad y codicia de la sociedad evocada en Casa de campo también ofrece la sugerencia de canibalismo como complemento extremo de las figuras evocadas a lo largo de la lectura.

Casa de campo es una obra multitonal en cuya factura se articulan estéticas divergentes, hasta opuestas. Conviven allí el realismo directo y una narrativa florida, ornamental, alusiva, que recuerda a la prosa modernista, así como un insistente y cortajeado uso de alusiones culturales de diversos períodos e idiomas. La partida de los mayores inaugura para los niños y el lector un viaje por los distintos niveles de la mansión que reproduce, en una figuración arquitectónica, aquello que a nivel de lenguaje se realiza en la tradición literaria.

¿Cuáles son los secretos develados durante estos viajes simultáneos? Uno de ellos tiene que ver con la biblioteca de la casa, un cuarto repleto de volúmenes elegantemente encuadernados cuya entrada les ha sido prohibida a los niños. En su interior está el desafortunado Adriano Gomara, padre de uno de los niños y prisionero del resto de la familia. Arabela, encargada de la biblioteca es quien tiene el privilegio - reservado solamente para ella entre todos los primos- de cuidar el recinto. El prestigio otorgado por su posición sugiere a los demás personajes que posee más información y saber que ellos, y es así que cuando le dice a Wenceslao, uno de sus primos cuya madre tiene la costumbre de vestirlo de niña, que la biblioteca contiene lomos vacíos encargados por su abuelo para cuidar las apariencias. Wenceslao termina sobrecogido ante la noticia. El poder de Arabela ya no puede ser referido a su familiaridad con la lecturas de los volúmenes; reside en otra fuente, más elusiva, desconcertante:

¿de dónde, si la "biblioteca" es así, saca Arabela tanta información? ¿Cómo sabe tantas cosas? La respuesta, en su cabeza, tomó la forma de un tropel de otras preguntas inmediatas: ¿pero es verdad que sabe tantas cosas? ¿O sólo lo creo yo, que sé muy pocas y lo creen los grandes cuando acuden a consultarla porque les acomoda que las sepa? $(33)^{1}$

El narrador nos asegura que los mayores conocían el verdadero carácter de la "biblioteca" y que la prohibición de entrar que habían creado para los niños so pretexto de protegerles la vista y el entendimiento era simplemente un ejercicio de poder que servía para demostrar el lugar de mando que ocupaban en la vida familiar.

Así, el saber de Arabela deviene algo cuyo vínculo con la lectura reside en apuntar el carácter ilusorio de la fuente escrita, lo ficticio de su información. Una vez que la hipótesis de su acceso a un gran inventario de autores e idiomas es dejada de lado, Arabela se convierte en un ente aun más elusivo para Wenceslao y el lector ya que encarna un saber simultáneamente predicado en el seno de los libros y fuera de toda lectura. El conocimiento de Arabela reside en su seguridad de que nada puede ser hallado en la biblioteca; su superioridad con respecto a sus primos es la indiferencia que siente ante los libros. Habituada a los gritos de Adriano Gomara, cuya frecuencia, cuando no está drogado o dormido,

\footnotetext{
' La paginación corresponde a José Donoso, Casa de campo (Barcelona: Seix Barral, 1978).
} 
puebla la biblioteca, Arabela puede burlarse de la sorpresa de Wenceslao. En esta escena de la novela la reacción de Wenceslao al encontrar a su padre y darse cuenta de la verdadera naturaleza de la biblioteca se contrapone a la figura de Arabela articulando de este modo la interrogación sobre la fuente del poder de Arabela. ¿Es su conocimiento una hipótesis como piensa Wenceslao- cuya necesidad reside en el deseo de niños y adultos? ¿O se trata de algo más básico, intransferible y perteneciente únicamente a Arabela?

Si en El amor en los tiempos del cólera, la intuición privilegiada de Fermina era fuente de la energía requerida para dejar de lado el libro y relacionarse con una supuesta vida, la fuerza de Arabela en Casa de campo se localiza en un dominio que, surgido de alternativas similares, alcanza una definición distinta. Arabela ríe. Su carcajada en contra de los posibles visos de sentimentalismo con los cuales podría imantarse el encuentro entre Wenceslao y su padre y la revelación acerca de la biblioteca, instituye un distanciamiento. La risa de Arabela recorre esta parte de la narración vaciándola de los sentimientos que desprecia, reinterpretando las situaciones en otro registro. Es así que aunque ella represente -como Fermina - la noción de que el ámbito de los libros debe abandonarse, su búsqueda se realiza bajo el vertiginoso signo de un humor destructivo mientras que la de Fermina culmina en una afirmación de las seguridades canonizadas por el amor en una apelación a la tradición literaria.

Una risa negra, cruel, superimpuesta a un miedo básico, no al amor, es presentada por Casa de campo como el referente privilegiado y virtual de la literatura, capaz de desmantelarla y revelarnos la vaciedad de los volúmenes en la biblioteca. ¿Tiene razón Arabela? ¿No hay contenido en los libros de ese recinto? O, en otras palabras, ¿cuán diferente es aquello que sucede en esta novela de lo legible en una biblioteca?

El juego de "La Marquesa salió a las cinco", ${ }^{2}$ traducido al castellano y, por eso, con la referencia francesa parcialmente perdida, es una de las claves que la novela ofrece para resolver estos interrogantes. Juvenal, cuyo nombre e imprecaciones a sus primos evocan al autor de las sátiras, organiza un teatro donde los niños intercambian papeles relacionándose entre sí en una economía de intercambios que se revela como perteneciente a los niveles que la novela sugiere intermitentemente como realidad o como ficción. En el estrato donde la realidad adquiere su mayor capacidad de desconcierto se alude al nacimiento de un niño como resultado de la unión entre dos primos, aun cuando la cronología no lo permitiría. En desafio abierto al desprecio de Valéry por el género novelístico, el juego de "La Marquesa salió a las cinco" despliega sus ficciones sin recurrir a versiones banales de la vida cotidiana. "La marquise est sortie a cinq heures" es traducida y reinscripta en un juego donde lo temporal apunta a su naturaleza fracturada, en oposición a la linearidad del sentido común.

El Dr. Urbino en El amor en los tiempos del cólera muere tratando de alcanzar a su loro, a quien ha tratado de enseñarle francés; sus últimas palabras ça y est serán completadas, intuimos, por su risueño verdugo en una mezcla de obediencia a la orden de repetir lo dicho por el amo y triunfo de la viveza criolla: ça y est. Al superimponer "La marquise est sortie a cinq heures" sobre el activo juego de "La Marquesa salió a las cinco", Casa de campo sugiere que la factura misma de lo literario está en el humor del desplazamiento.

${ }^{2}$ Esta frase aparece adjudicada a Valéry por André Breton en el Segundo Manifiesto Surrealista. 
Las interacciones de los personajes, vistas a través de la ausencia de libros en la biblioteca señala que quien desee ir en busca de aquello que convencionalmente se adjudica al dominio de la lectura, debe internarse en un peligroso juego cuyas transformaciones son la mejor encarnación ${ }^{3}$ de las meras sugerencias hallables en cualquier volumen. ${ }^{4}$

La relación entre literatura y vida es doblemente inscripta en Casa de campo. Por un lado, el juego de los primos produce un nivel de ficción dentro de la ficción con límites borrados por la hipótesis del nacimiento de un niño real, ${ }^{5}$ con ecos del embarazo en $E l$ obsceno pájaro de la noche. ${ }^{6}$ Por otro, un narrador controlador interviene en el texto enmarcando este estrato de la novela con sus comentarios y un encuentro casual -al final- con uno de los miembros de la familia que le asegura que la historia es aburrida, está mal escrita, llena de malinterpretaciones y caprichos. El efecto es invitar una relectura desde un nuevo punto de vista, como sucede en Cien años de soledad de García Márquez. Mientras que en el caso de esta novela de García Márquez, la relectura crítica terminaría con la "vida" de la familia, demostrando que es meramente una de las instancias de un manuscrito, en Casa de campo el efecto es distinto. La opinión del miembro de la familia Ventura invocada al final tiene el efecto de aplacar el miedo y la ansiedad producidos durante la narrativa así como reducir el fulgor de la riqueza familiar. La historia pierde sus aristas y cambia momentáneamente como si estuviéramos en un momento de "La Marquesa salió a las cinco", volviéndose una de esas insípidas narraciones que tanto Valéry como Donoso recibirían con condescendencia. Una vez que se expulsa el miedo también, paradójicamente, se acaba con el placer de la lectura y el interés en la historia de los personajes.

\section{VISTO POR UN PERRO HAMBRIENTO}

¿Debemos entonces leer Casa de campo como el moderado aunque eficaz regreso de un narrador capaz de minar el desprecio de Valéry por los intentos novelísticos? La novela despliega en este sentido un escenario más amplio en el cual las fricciones entre arte y un supuesto dominio llamado vida retornan en otro registro.

Abundan en la historia menciones de telas y tapices. A diferencia de los libros encierran claves y augurios y en su eficacia predictiva e interpretativa adquieren un notable privilegio. Una versión de "L'Embarquement pour Cythère"7 colgada de la pared es descripta al mismo

\footnotetext{
${ }^{3}$ Ver, por ejemplo, el tratamiento del oro en esta novela y relacionarlo con la perspectiva siniestra en la cual reinscribe la literatura de Darío.

${ }^{4}$ El poder de Arabela en esta novela es equiparable al que ejercen en otras obras de Donoso las mujeres mayores - las "viejas"- como en El obsceno pájaro de la noche o los vagabundos en "Gaspard de la nuit".

${ }^{5}$ Los nombres vagamente arcaicos de los primos, en contraste con las referencias contemporáneas de algunas partes del texto refuerzan el sentido transhistórico de la narrativa.

6 José Donoso, El obsceno pájaro de la noche (Barcelona: Seix Barral, 1970).

7 Esta obra es también alusiva al poema de Baudelaire "Un voyage en Cythère". La consideración conjunta del tapiz y el poema de Baudelaire sintetiza el deterioro que se avecina en la novela. Los últimos versos: "-Ah! Seigneur! donnez-moi la force et le courage/ De contempler mon coeur et mon corps sans dégout!" sugieren la desesperanza que cundira entre los personajes. Ver Charles Baudelaire, "Un voyage en Cythère", Les Fleurs du mal en Oeuvres Complètes (París: Bibliotheque de la Pleiade, 1961) 111-113.
} 
tiempo que se nos hace saber de los planes de partida de los mayores. Así, pinturas y tapices entran a la narrativa en plena participación no sólo de la anticipación del futuro de la anécdota sino también suscitando ciertos hechos fuera del modo de su propia representación. Uno de los sirvientes, Juan Pérez, asume la tarea de restaurar un fresco trompe l'oeil colgado de una de las paredes de la mansión. La descripción de su tarea sugiere que el fresco tiene la capacidad de percibir, no es un mero ornamento:

Este ojo, se dijo Juan Pérez-y untó su pincel en brillo glauco para pintar un foco en las pupilas del galgo que con su pata entreabría la puerta para asomarse al salón- será mi ojo. Lo registrará todo: cuando yo no esté, permanecerá aquí, vigilándolos (227).

La restauración hecha por Juan Pérez enfatiza una estructura para la agresividad de cada uno de los componentes del fresco. Este perro no es un animal doméstico, su agresividad no ha sido canalizada en un entrenamiento para la caza; es, por el contrario, una suerte de complemento para la furia de Juan Pérez:

Pero quería dejar bien claro que él no era ese cortesano, galgo famélico cuyas costillas negras se disponía a acentuar con sombras. Cuanto su pincel de restaurador tocaba parecía transformarse en un engendro alucinado. Sus esbirros, suspendidos por andamios y poleas a distintas alturas sobre la faz del fresco, se encargaban de transformar imperceptiblemente a las diosas retozonas en arpías, a las nubes sonrosadas en tormentas. Este perro vería con una minuciosidad equivalente a su hambre todo aquello que él no podía ver porque se hallaba con la nariz en un palmo del muro, cercado por potes de color, su espalda vuelta hacia la sala ... (323-324).

Juan Pérez da el ojo al perro; el ojo del perro es Juan Pérez pero el perro ve más que Juan Pérez a pesar de ser el producto de su restauración. Al montar guardia en el fresco, la amenaza del perro redime a Juan Pérez de la humillación implicada en la posición de sirviente. La fría y cruel mirada del perro desmantela las reglas del teatro del poder y las reformula sin explicitar su alternativa.

La mirada famélica del perro parece impulsar el pincel restaurador, tornando a sus figuras en alucinadas. ¿Qué han visto? ¿Qué ha trastornado sus apariencias a tal punto? Intuimos que no se trata de algo que hayan visto sino de la manera en que son contemplados. El perro ha acabado con las diosas retozonas, con los paseos y flirteos, con la armonía de las relaciones de poder; en su lugar, su hambre ha descubierto la furia y el hambre de los participantes en el fresco. El perro no ataca a nadie. Su función es más importante y consiste en redefinir el tono de los intercambios y, al hacerlo, mostrar su naturaleza. Arabela revela la vaciedad de la biblioteca y desarrolla la indiferencia necesaria para distanciarse del dolor de Adriano Gomara; el perro, más allá de toda palabra, está allí para completar las lecciones de su humor llevándolas más lejos, hacia la representación del orden social en el registro de una mirada famélica. No se trata de libros en este momento sino de un fresco trompe l'oeil que nos repite con mayor énfasis que aquello que realmente pesa, lo sustancial, es distinto de lo hallable en volúmenes o en las apariencias inmediatas de la pintura. Es lo referido de este modo algo que llamaríamos "realidad". Los personajes semi-animados que se entremezclan con quienes habitan el fresco trompe l'oeil no afirman 
una oposición nítida entre arte y realidad; por el contrario tienden a proponer un entendimiento del arte que impregne nuestra perspectiva - pesadillesca - de la realidad.

El perro observa, famélico, encuadrando lo que ve en la perspectiva tendenciosa de su odio. Su mirada es transformadora y paralizante.

Otro perro, casi narrador silencioso debido a la función que cumple en una reinterpretación de la historia, aparece en la breve novela La misteriosa desaparición de la marquesita de Loria $^{8}$ de Donoso. La novela se abre como un texto ligero, lúdicamente erótico que toma lugar a principios del siglo. Una joven muchacha, educada en un convento, se casa y pierde a su marido al poco tiempo iniciando, de este modo, simultáneamente su viudez y sus placeres sexuales en una clave intensa y transgresiva. El contexto es elegante, hasta lujoso, su casa heredada después de la boda está poblada de ornamentos cuya evocación literaria tiene ecos de la sensibilidad modernista.

La armonía del universo de la marquesita de Loria es trastornada por su relación amorosa con un hombre que posee un perro llamado Luna. Blanca, epíteto de Luna, experimenta una fuerte sensación al verlo, de una intensidad cuya sorpresa sería narrativamente considerable sin el guiño al lector representado por el juego entre las palabras "blanca" y "luna":

\begin{abstract}
Al abrir, en cambio, la puerta de su dormitorio oscuro sintió que su corazón daba tal brinco de sobresalto en su pecho que casi le cortó a respiración: allá estaban los dos ojos como dos lunas nadando en ese infinito espacio oscuro y caliente y aromado. Percibió un nuevo horizonte de potentes olores primitivos, esenciales. No encendió la luz. Los ojos se fueron acercando muy despacio hacia ella en la oscuridad hasta que vio el fondo mismo de esas pupilas huecas, el otro lado de esas redomas cuya iridiscencia hacía destellar gotas de baba en su hocico, que grunía. Alzando de repente el grunido Luna se lanzó sobre ella tirándola al suelo encima de las astillas de las botellas de cristal, abofeteándola con sus patas ásperas, desnudándola otra vez con el hocico hirviente ... (162-163).
\end{abstract}

El perro libera a Blanca cuando "se dio cuenta de que Blanca se disolvía en el primer espasmo de esa noche". La voluptuosidad y el placer de Blanca en ser arrasada por el poder de Luna son evidentes. A la mañana siguiente después de mirarse, rasguñada y amorotonada y ver al perro fuera, por la ventana, Blanca decide que no le contará a nadie lo ocurrido. Será un secreto. Hay una ruptura con un pretendiente y numerosos indicios de que la novela ha cambiado de signo, convirtiéndose en el recuento de la relación entre Blanca y Luna. Entre luna y su epíteto.

La incursión destructiva de Luna en el contexto ornamental de la novela se torna hiperbólica cuando desaparece Blanca, después de haber estado en un automóvil con un hombre con quien ha tenido relaciones sexuales. Al ser acusado de su asesinato, el hombre replica que él no es culpable porque un animal enorme se la llevó en el medio de la noche. Nadie le cree y es encarcelado, pero el lector que comparte el secreto y es depositario de la otra versión, aquella que, apenas articulada por el perro, señala su conexión necesaria con Blanca, reconoce la clave de violencia y placer por la cual se define la relación.

\footnotetext{
${ }^{8}$ La paginación corresponde a: José Donoso, La misteriosa desaparición de la marquesita de Loria (Barcelona: Seix Barral, 1980).
} 
Después de haber visto y haber sido vista por la vaciedad en el fondo de las pupilas de Luna, el contexto frívolo de Blanca es desmantelado. Ella se entrega objeto por objeto, en el detalle de su ropa y de su cuerpo, al apetito del perro, a la necesidad encarnada en su mirada. En La misteriosa desaparición de la marquesita de Loria la virtualidad de la mirada del perro articula con mayor intensidad la problemática de Casa de campo. Mientras que el perro restaurado por Juan Pérez sólo vigila, Luna es el desmantelador privilegiado de ornamentos inútiles, el destructor supremo, capaz también de revelarle a Blanca el dolor que acecha en el centro del placer precipitándola, así, al reconocimiento y consumación de su unión. Blanca y Luna, blanca luna, esgrimen una amenaza para el lector que cada noche renueva su propia visión y teatro para la blanca luna.

QUÉ CARA Y QUÉ ROPA

El mundo ornamental de Blanca, sus muebles, ropa y accesorios son destruidos por la energía del perro. La incertidumbre acerca de la "verdadera" existencia del perro otorga a su poder destructivo cierto desconcierto. La hipótesis de que el perro existe dentro de Blanca y no en el mundo exterior incorpora la amenaza que representa como un reconocimiento de la vaciedad de la persona. Así, Blanca sería un mero pero necesario adjetivo para Luna, la fuerza que la impulsa hacia el agujero negro de su autorrepresentación, la verdad última acerca de su carácter banal.

Las huellas dejadas por Blanca son la hebilla de plata de la cloche, un zapato francés, y el Patek Philippe de oro (194), fragmentos recuperados como signos de su unicidad y claves para develar el supuesto asesinato. La manufacturación que Blanca hace de sí misma a través de la adquisición de objetos es parte de una sostenida meditación sobre el consumo que permea la obra de Donoso. Una de las novelas de Tres novelitas burguesas, ${ }^{9}$ "Chatanooga Choochoo" presenta una galería de personajes adinerados con la libertad de consumir cultura y objetos.

Sylvia, una modelo de cara supuestamente "perfecta" anuda hiperbólicamente aquello que de un modo u otro aparece en el resto de los personajes. Su cara debe ser literalmente dibujada para cada fotografía. Aquello que era sólo intuición de vacío en Blanca es celebración de posibilidades de lucro y de erotismo en el de Sylvia:

La sensación de poder mágico de Sylvia, la mujer adjetivo, las mujer decoración, la mujer desmontable y plegable que presenta todas las comodidades de la vida moderna, privada de todo, hasta de individualidad y unidad y por eso poderosa, debe haber primado durante mis sueños que no alcanzaba a recordar más que en forma de destellos, y porque no alcanzaba a atraparlos y porque amanecí temiéndola, lo primero que se presentó ante mí al abrir los ojos fue una incontrolable urgencia por ver a Sylvia otra vez. ¿Qué cara tenía ahora? ¿Qué vestido iba a tener puesto, ella que dependía tanto de su ropa, y una echarpe anundada de cierta manera para hacerla cambiar entera, no sólo fisicamente sino como persona? ... pero más urgente que eso, o quizá lo que le daba fuerza y forma a esa urgencia, era la necesidad de borrarle la cara con Vanishing Cream y entregarme al gozo de pintársela y maquillársela de nuevo (70).

\footnotetext{
${ }^{9}$ La paginación corresponde a: José Donoso, Tres novelitas burguesas (Barcelona: Seix Barral,
} 1973). 
Al bailar junto con una amiga al son de "Chatanooga Choochoo", Sylvia sugiere los términos de una inquietante pareja de mellizas. Ella, capaz de maquillarse para parecerse a cualquier mujer podría también representar el estrato más profundo de todas. La elocuente y nostálgica celebración de Huidobro en Altazor, "Todas las mujeres se te parecen / ahora que no te pareces a ninguna", es reinscripta en una oscura clave humorística. El deseo que el narrador siente por Sylvia lo lleva al vacío y su placer se localiza en el simulacro de una plenitud momentánea: borrar la cara y maquillarla de nuevo.

La Vanishing Cream (en inglés: crema de esfumarse) y el maquillaje entran al texto en sus acepciones literales y en tanto objetos de consumo. Sylvia es el producto cosmético por excelencia en esta novela, idealmente sin cara (des-carada), manejable y, debido a ello, promesa de belleza perfecta con cada nuevo invento del mercado. La mujer del narrador, Magdalena, posee un rostro estable pero debe luchar en contra de su tendencia a emerger detras del maquillaje de modo de poder triunfar y ser, como Sylvia, la belleza de las portadas de las revistas.

Cuando el narrador maquilla a Magdalena hay una voluptuosidad con ecos eróticos; es una suerte de iniciación para la cual parece haber estado preparado con la naturalidad de los actos necesarios. El ejercicio se instala profundamente en su conciencia, le trae memorias de su niñez, momentos en los cuales llegó a autodefinirse. Es un juego con el poder revelatorio de la experiencia amorosa:

Era un juego, mascarada, máscara ... y recordé cuando nos disfrazábamos en los altillos de las casa de campo de mi ninez: metíamos toda la cabeza dentro de una media de seda transparente que conservaba todas nuestras facciones individuales disimulándolas, pintábamos otras caras, la cara feroz del lobo malo, la cara blanca y pudibunda de la princesa, la narizota feroz de la bruja, las arrugas de la anciana, los bigotes y las barbas del patriarca, guardando, sin embargo, nuestras características facciones bajo los rostros pintados en la falsa carne transparente de la media de seda. Así con Magdalena ahora que no era Magdalena, sino una mutación del rostro de Sylvia, y Sylvia, a su vez era todas las variaciones posibles del rostro ovoide de Sylvia; que a su vez eran todas las variaciones posibles de los mitológicos aparecían en las revistas de modas y en los anuncios de los periódicos, que a su vez eran las infinitas variaciones del rostro propuesto por algún creador de maquillajes en combinación con un fabricante, que lo crearía recordando algún rostro de su niñez ... (76-77).

Cuando Magdalena trata de imitar la apariencia de Sylvia es como si ella misma se estuviera recubriendo la cara con una media; un solo error, una arruga, una corrida y sus propias facciones podrían alterar la perfección del maquillaje. Al tratar de emular a Sylvia, Magdalena hace lo opuesto de la mimesis convencional. En su caso no se trata de referirse a un original más auténtico, más sustancial, más estable que las proliferantes imitaciones. El ideal, por el contrario, es no tener cara alguna para, entonces, en un ejercicio paradójico asumir todas los rostros posibles. ${ }^{10}$

El ejercicio que junta a Magdalena con su marido en el momento de ser maquillada es una parodia de los poderes transformadores del amor. El placer experimentado por el

10 Ver Vicente Huidobro, “Altazor”, Canto II. 
marido al ir alcanzando la configuración que anhela en el rostro de Magdalena sugiere que la identificación con los fragmentos de representación proporcionados por la publicidad y el arte son todo lo que poseemos para articular los términos de nuestro deseo. Sin embargo, "Chatanooga Choochoo" va más lejos; no nos presenta meramente una parodia de la pareja ideal del mundo de consumo, con una mujer que obedientemente sigue los caprichos de su marido. La voluptuosidad de las relaciones sexuales entre el narrador y Sylvia alude a la excepcionalidad del contrato consumado, al privilegio que usufructa el narrador y la dificultad de repetirlo; es decir, de articularlo en la economía de sus placeres. La cabeza en forma de huevo de Sylvia, su carencia de facciones cuando está maquillada, su mudez debido a que no tiene realmente boca, son elementos para el desborde de ternura del narrador que la identifica como la mujer ideal. Hacerle hablar es fácil. Cuando quiere, la sigue hasta el baño y le recorta una boca con la misma facilidad con que maquilla a Magdalena. Una forma hiperbólica y detallada de hacer el amor se delinea en este momento de la novela, con su concomitante paréntesis utópico.

Lo primero que hace Sylvia después de que el narrador le recorta una boca es cantar la anodina "Chatanooga Choochoo" y después le da un beso:

Entonces se calló bruscamente, se acerco a mí y, poniendo su boca recién recortada sobre la mía, me besó. Sin poder resistir el impulso, la tomé en mis brazos, y ese beso - que ella, sin duda, me daba, para probar la eficacia completa de su boca en todas sus funciones- me hizo conocer la satisfacción de besar y quizás hasta amar a una mujer que no es completa: el poder del hombre que no corta lengua ni pone cinturones de castidad por ser primitivos, sino que sabe quitarle o ponerle la boca para someterla, desarmarla quitándole los brazos, el pelo en forma de peluca, los ojos en forma de pestańas postizas, cejas, sombras azules, quitarle mediante algún interesante mecanismo el sexo mismo para que lo use sólo en el momento en que uno lo necesita, que todo, todo en ella depende de la voluntad del hombre ... (42-43).

Así como en Dormir al sol de Adolfo Bioy Casares, ${ }^{11}$ la historia del hombre que esperaba transformar a su mujer en la perfecta esposa mediante una operación en la cual su alma sería cambiada por la de un perro nos conduce a un final pesadillesco, donde la fantasía de dominación victimiza a quien quiere tomar control; "Chatanooga Choochoo" se burla de quienes intentan autoritarismos en el placer. Con Sylvia y Magdalena como público, Ramón —el esposo de Sylvia-y el narrador luciendo trajes idénticos cantan y se mueven al son de "Chatannooga Choochoo". La lógica de las transformaciones sufridas por Sylvia y Magdalena rige también a los hombres. El poder encantatorio y sometedor de la canción los ha afectado. La música, banal y repetitiva nos señala que el teatro de dominación donde cada uno, es finalmente sometido por otro no es necesariamente una figuración oscura según las reglas prevalentes en la representación de esa fantasía, sino que también subyace en la anodina recurrencia de "Chatanooga Choo-choo".

Blanca, arrebatada por Luna en La misteriosa desaparición de la marquesita de Loria, es una figuración del deseo en sus connotaciones autodestructivas; su ubicuidad en el

\footnotetext{
${ }^{11}$ Este aspecto se desarrolla en detalle en el capítulo dedicado a Bioy Casares.
} 
subtexto de "Chatanooga Choochoo" devela un vacío más siniestro que el de la mirada de Luna pero con idéntico poder, esta vez encarnado en el rostro agresivamente desdibujado del amante ideal.

\section{APOSTAR A LOS PERROS: EL JUEGO DE PÉRDIDA COMPLETA}

A diferencia de otras obras de Donoso, La desesperanza, ${ }^{12}$ publicada en 1986, tiene un contexto netamente político. Dos personajes, Mañungo -de vuelta en Santiago de Europa el día de la muerte de Matilde Neruda - y Judit se encuentran en la calle después del toque de queda. La novela narra las tensiones de la noche y presenta una galería de personajes cuyos intercambios reinscriben gran parte de la problemática de Donoso en una clave de explícita historicidad.

Son los perros nuevamente quienes proveen las imágenes para iluminar el sentido de lo narrado. Cuando Mañungo y Judit están buscando un lugar en las calles desiertas para pasar la noche fuera del alcance de las autoridades, Judit ve a un grupo de perros en la calle en persecución de una perrita. Corren detrás de ella, la cercan a ratos con la intención se nos dice- de violarla. Los peligros que acechan a la perrita son narrados desde una perspectiva que, al humanizarla, la ponen en una situación que guarda no pocos paralelismos con la de Judit. Como en "Recortes de prensa" de Julio Cortázar, la violencia nocturna es referida en un discurso de claustrofobia generalizante:

En una esquina vieron el tumulto de perros en la acera de enfrente. El perro enorme enloquecido, y abajo, entre sus patas, con el pelaje pegado a su desnudez, la perrita blanca esperaba, relamiéndose, a que la bestia cumpliera su trivial impulso. Los demás perros formaban alrededor suyo un arisco círculo pendenciero, expectante, alrededor del macho que no lograba ayuntarse satisfactoriamente. Al ver a la perrita, Judit, con un grito, se desprendió de Mañungo, y cruzando la calle, sin importarle quien la pudiera ver ni oír, gritaba, váyanse, déjenla, perdónenla. Pero los perros no estaban dispuestos a dejar a la perrita cuyas ojeras parecían más profundas y viciosas, y su rostro más concentrado y más pálido, aceptante de todos los perros que quisieran poseerla (192193).

Mañungo, fuera del círculo formado por los perros, en directa alusión a su papel en la vida política de Chile, le pide a Judit, que ha entrado en el círculo de los perros que salga, que no se arriesgue. Ella sin embargo, padece el peligro de los perros desde adentro en un acto aparentemente voluntario.

La perrita, por su parte, accede al deseo de los perros y actúa con las reglas de quien sólo desea sobrevivir; es una obediente actriz en el juego impuesto por la fuerza. Pero Judit interfiere en contra de su decisión, se interpone entre ella y los perros en un intento de defenderla. De pronto, Judit, pistola en mano, dispara:

Todos debían morir, machos indiferenciados que adheridos a ella la ensuciaban. En el medio de la leva, en cambio, la perrita blanca, única, delicada, irónica, como si esto

${ }^{12}$ Ver José Donoso, La desesperanza (Barcelona: Seix Barral, 1986). 
transcurriera en un salón digno de su alcurnia, centraba la furia desatada por sus circunstancias en la fatiga de sus ojeras y en la melancólica sonrisa de quien no puede escapar a su destino, pero por lo menos puede jugar. Judit no podía llegar hasta la perrita porque los animales mordían sus piernas chorreadas. Estaba a un metro de ella. ... desde las patas del perro overo en el centro del círculo infernal, tierna, limpia, fatigada, le sonrió a Judit, su cómplice, su salvadora, su hermana, que apuntó con la pistola y le disparó a su cabeza: el cuerpo dio un respingo y la perrita cayó inerte (193-194).

Al intervenir en el conflicto Judit destruye la estrategia de supervivencia de la perrita; su ineficacia en salvarle la vida enfatiza la dificultad de cualquier resistencia a la ley de la fuerza. Es en esta escena donde la desesperanza del título de la novela se formula del modo más intenso. El intento de poner fin a la agresión se torna en su opuesto. La perrita recibe el mensaje de la jauría y opta por reconocer su poder y aceptar su condición de víctima; Judit, al matarla, la convierte en una mártir a desgano de una causa innominada.

¿Ha muerto con dignidad la perrita? ¿O ha quedado unida, marcada por la jauría, debido a su colaboración con el juego propuesto? Tanto Noemí en "Recortes de prensa" de Cortázar como Molina en El beso de la mujer araña de Manuel Puig intentan penetrar e intervenir en un ámbito que responda a este interrogante. Es a través de juegos, escenas, combinatorias que Donoso despliega aproximaciones a una respuesta. No se trata, como en Rayuela o "Final del Juego" de Cortázar, de juegos pre-existentes sino como con "La Marquesa salió a las cinco" de otros, inventados, cuya función es destacar el carácter de aquellos que conforman la vida en sociedad.

El obsceno pájaro de la noche, esa sombría novela narrada por un personaje alternativamente llamado Humberto Peñaloza o "El Mudito", es el momento de iniciación de gran parte de las figuraciones presentes en obras posteriores de Donoso. Como en Casa de campo, un espacio arquitectónico opera como una matriz para los acaeceres de la novela. Máscaras, hacer el amor, cambiar de ropa, ponerse harapos proliferan en cadenas de significación que anticipan la poética de autodestrucción de La misteriosa desaparición de la marquesita de Loria, "Átomo verde número cinco" y las novelas reunidas bajo el título de Cuatro para Delfina. ${ }^{13}$

Una perra amarilla aparece en El obsceno pájaro de la noche como testigo de un secreto indecible que une a una niña, su padre y una mujer presentada alternativamente como nana, anciana y bruja. La perra atemoriza a quienes hacen el amor; su mirada los fija en la imposibilidad del acto. Cierra la novela, silenciosa y veloz, portadora de enigmas. También ella está sujeta a transformaciones y deviene un juego, "la perra amarilla", que las viejas del convento repiten incansablemente, apostando todo lo que tienen, hasta sus dentaduras postizas. Pobres pero insaciables jugadoras, las viejas pierden sus pertenencias, envueltas en deshechos de periódicos.

Los paquetes de las viejas son su individualidad y "la perra amarilla" es un juego que todo lo arrasa, haciendo circular los papeles y las cosas. Siempre gana la perra amarilla porque a pesar de los avatares de cada jugada ya no hay dueña de paquete, sólo desperdicios, fragmentos ya irreconciliables de vidas que sólo existen como hipótesis.

${ }^{13}$ José Donoso, Cuatro para Delfina (Barcelona: Seix Barral, 1982). 
¿Quién es esta perra amarilla? ¿Quiénes son estos perros que proliferan en la obra de Donoso? ¿Hay una lección o acaso una invitación en las miradas que paralizan, la furia que viola y que convierte en asesina a quien desea salvar a una perrita? Eminentemente no domesticables, los perros traen a los relatos de Donoso una poética de lo indecible, una traducción del deseo en tanto bestialidad esencial, traducción última de lo político, significación más allá de lo sexual. Perder la cara, cambiar de ropa, inventarse rostros ... Detrás de todo eso hay un perro, principio de descontrol, energía desmanteladora que ferozmente se burla, como Arabela, de quienes creen que hay alguna otra enseñanza encerrada en los volúmenes de la biblioteca. 